\title{
Addressing severe slope failure hazards along Sichuan-Tibet Highway in Southwestern China
}

\author{
1. Institute of Geology and Geophysics, Chinese Academy of Sciences, Beijing 100029, China, E-mail:jun94@mail.igcas.ac.cn \\ 2. Department of Civil Engineering, The University of Hong Kong, Hong Kong, China \\ 3. Institute of Mountain Hazards and Environment, Chinese Academy of Sciences \& Water Conservancy Ministry, Chengdu 610041, China
}

This paper presents the results of recent field investigations on the geological hazards along the Sichuan-Tibet Highway in Southwestern China. It was found that one section of the highway has been facing severe problems in slope failure. This is the section between Linzhi and Basu and it has been the most dangerous part of the highway system to road users over the last fifty years. Based on the examination of structural geology, Quaternary geology, stratigraphy and petrography, this paper presents the classification, distribution and hazard levels of the slope failures along the highway section. The failures usually occurred in slopes comprising Quaternary glacial deposits, fluvio-lacustrine deposits and residual soils. They can be classified as landslides, mud-rock flows, grain flows on slopes and rock avalanches. They are caused by four main factors: a) intense active tectonic movements, $b$ ) on-going alpine canyon relief, c) heavy precipitation and d) irrational human activities. The paper further discusses the engineering measures adopted by the relevant organizations over the past fifty years. Based on the investigations, the paper summarizes some useful recommendations to effectively address and mitigate the severe slope failure hazard problem for safe operation of the highway and future railway systems.

\section{Introduction}

The Sichuan-Tibet Highway is $2155 \mathrm{~km}$ long and is located in the southeastern region of the Tibetan Plateau (Figure 1). It was constructed in 1950. Since then, it has offered the only route for surface transportation between Chengdu and Lhasa and has been of extreme importance to the nation. It is also well known in the region, however, that numerous slope failures have happened along the highway and resulted in massive losses in property, roads, bridges and human life. The recent investigation of the slope failure history along the road showed that the highway section between Linzhi and Basu in the north of Yarlung-Tsangpo Canyon is the section of the most intense and serious slope failures and hazards among the entire highway system. This section is $427 \mathrm{~km}$ long and has many zones of potentially unstable slopes. Its slope failure risk is still extremely high.

Over the last 50 years, lots of slope failure investigations and remediation work have been carried out by many geologists, geomorphologists and highway engineers in the region (BGMRXAR,
1993; 1994; 1995). Details of the previous investigations and results have been well documented in Chinese literature, especially the two recent publications by IMHE et al. (1995) and IMHE and ITS (1999). Literature review of the present investigation revealed that the majority of the great efforts, however, have not been published in English literature. Most of the relevant publications in English literature are on the regional geology and active tectonics (Brookfield, 1998; Coleman and Hodges, 1995; Fielding, 1996; Hewitt, 1999; Hodges, 2000; Li, 1996; Molnar, 1986; Pan, 1999; Ruddiman, 1998).

This paper is intended to present the summative results of our integrated investigation on the severest slope failure cases, their key features and the remediation measures taken to prevent their hazards on the highway section. In the study, we applied our integrated interdisciplinary expertise to the examination of relevant issues on many aspects. These aspects include structural geology, engineering geology, soil and rock mechanics, geomorphology and geotechnical engineering. The investigation covers the strata, slope failure mechanism, rock and soil properties and characteristics, as well as the preventive and remediation engineering measures that have been adopted on the highway. Based on the findings of the investigation, the paper will make useful recommendations for better design and construction of engineering measures to effectively prevent slope failures in the region. In particular, it is known that the government is planning to upgrade the existing highway and construct a railway along the highway. The findings of this paper would be useful to the investigation, design and construction of the new highway and railway systems in the region.

\section{Active regional tectonics and consequences}

It has been well recognized that the Tibetan Plateau has been rising since the Indian Plate collided with the Eurasian Plate about 45 million years ago. The ongoing rise of the Tibetan Plateau and the Himalayas clearly shows that the Indian Plate is still being thrust into the Eurasian Plate. It is estimated that since the two plates collided, the Indian Plate has been moving into the Eurasian Plate at about 50 $\mathrm{mm}$ per year (Molnar, 1986). This continued thrust has resulted in about $2500 \mathrm{~km}$ of crustal shortening of the Tibetan Plateau, which is in a stressed state of high compression and is still rising. The uplift process of the Tibetan Plateau and the Himalayas may be expressed in the following tectonic movement model: intra-continental collision, crustal layer thickening and isostatic adjustment (Li, 1996). More evidence showing the rising of Tibetan Plateau can be found in recent publications by Coleman and Hodges (1995), Fielding (1996) and Ruddiman (1998).

As discussed by Keller and Pinter (1996) and Pan (1999), the continued thrust of the Indian Plate into the Eurasian Plate has been accompanied by the following three geological phenomena: a) evident movements of regional thrust faults; b) active continental extru- 

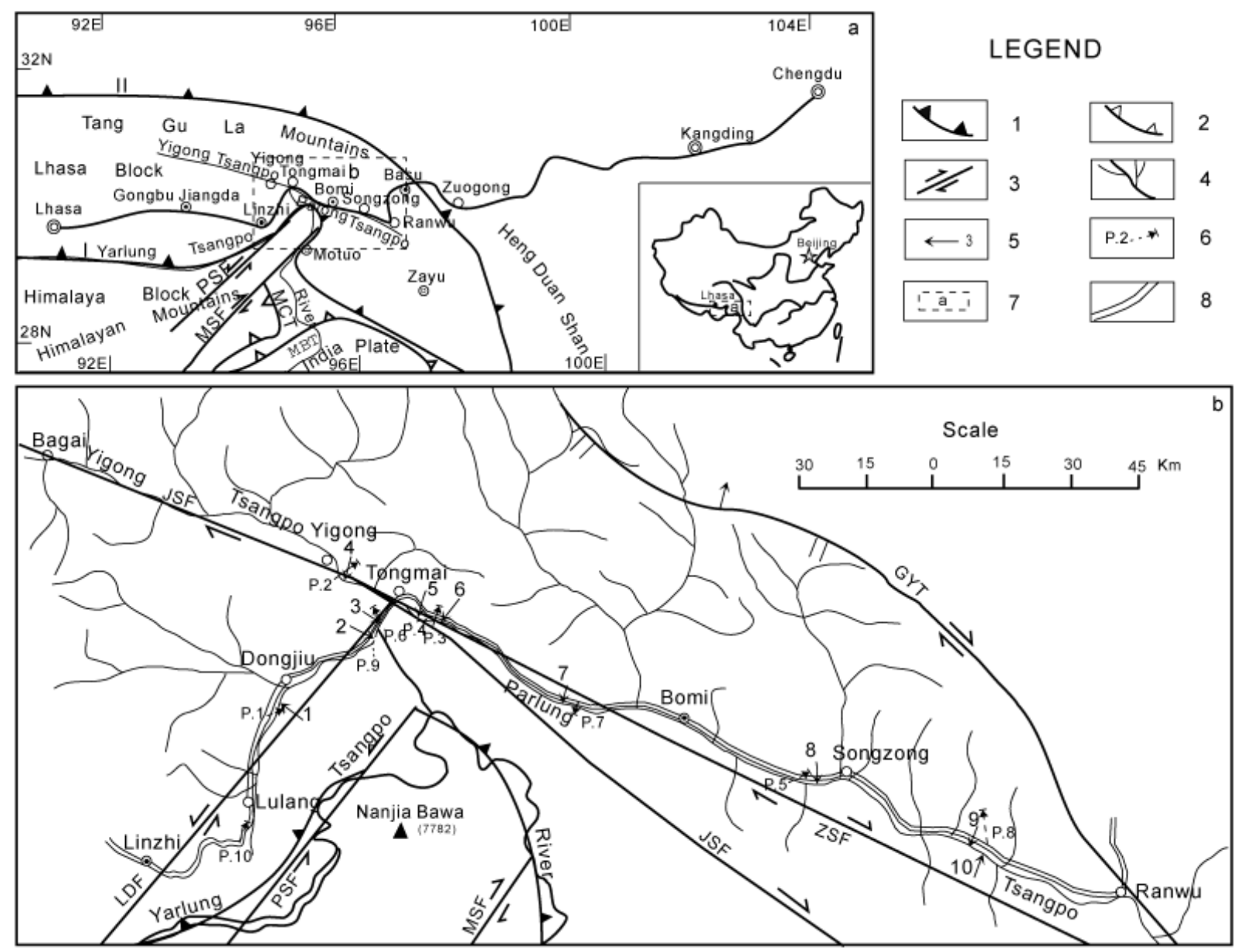

Figure 1 Geological setting and distribution of geological hazards along the highway section (modified after IMHE et al., 1995; Pan, 1999; Ding and Zhong, 1999).

a. Map of regional Tectonics and the Sichuan-Tibet Highway (Lhasa-Chengdu). b. Sketch map of the distribution of geological hazards. 1-suture I: Yarlung Tsangpo Suture, II: Bangong Nujiang Suture; 2-large-scale thrust fault: MBT = Main Boundary thrust; MCT = Main Central thrust; 3-strike-slip fault: GYT = Guyu strike-slip and thrust fault; JSF = Jiali strike-slip fault; LDF = Linzhi-Dongjiu strike-slip fault; $M S F=$ Motuo strike-slip fault; PSF = Paiqu strike-slip fault; ZSF = Zayu strike-slip fault; 4-streams; 5-geological hazard location: (1) = Dongjiu landslide; (2) = Peilong avalanche; (3) = Peilong mud-rock flow; (4) = Yigong landslide; (5) = Jiamaqimei mud-rock flow; (6) $=102$ landslide; (7) = Guxiang mud-rock flow; (8) = Songzong landslide; (9) = grain-flow; (10) = Midui mud-rock flow; 6-standpoint and line of vision; 7-figure location; 8-Sichuan-Tibet highway.

sion; and c) strong ground uplift and erosion. The relationship between the ground uplift and the ground erosion has been examined by a number of scientists (e.g. Fielding, 1996). The ground uplift and erosion have been controlling the river stream networks and configuration and mass movements in the entire region. Consequently, they have dominated the evolution of the landform in the Tibetan Plateau and Himalayan mountains (Brookfield, 1998). More detailed information on the active tectonics in the Himalayas and Southern Tibet can be found in recent publications by Pan (1999) and Hodges (2000).

It has been well recognized that strong tectonic movements and major active geological structures usually control the origin and evolution of geological hazards in a region (Parise et al., 1997; Schenk and Bulmer, 1998; Philip and Ritz, 1999; Strecker and Marrett, 1999), especially earthquake-induced landslides (Keefer, 1994). In particular, a number of investigations have been carried out on the combined role of geomorphological processes and tectonic activities on geological hazards around the world (e.g. Penck, 1953; Arrowsmith et al., 1996). These studies and results are instructive to the present investigation for addressing the frequent slope failures and their severe hazards along the highway system. The strong neotectonic movements and uplift in the Tibetan Plateau have resulted in many massive slope failures in the forms of landslides, debris flows, rock avalanches and mud-rock flows in the mountain regions.

Major slope failures and their severe hazards have been frequently reported at many locations in the southern Himalayas of Nepal, Pakistan and India. The most notable examples are the Tsergo Ri landslide with a debris volume of up to several billions of cubic meters in the Langtang Himal, Nepal (Ibetsberger, 1996; Schramm et al., 1998), the rock slides and landslides in the Kali Gandaki valley of high Himalayas, Nepal (Fort, 2000), the catastrophic rock avalanches in the Karakoram Himalaya in Northern Pakistan (Hewitt, 1999), and the landslide zone in the Yamuna valley of the Garhwal Himalayas, India (Pachauri et al., 1998). It is noted that the slope failure investigations in this region usually adopt the following methods: satellite digital data analysis, stereo-projection, site reconnaissance, petrological analysis and hazard zoning (Pachauri et al., 1998). The present investigation observed that these methods are also usually adopted by the geologists and geomorphologists in Sichuan and Tibet for the investigation and evaluation of the slope failure hazards along the highway system (IMHE et al., 1995; IMHE and ITS, 1999). 


\section{Active geological phenomena along the highway}

The highway section between Linzhi and Basu is situated at the Gangdise Island Arc Terrain (i.e. Lhasa Block) and between the Bangong Nujiang Suture and the Yarlung Tsangpo Suture (Figure 1). The continued thrust of the Indian Plate into the Eurasian Plate has resulted in the large-scale uplifting of the Himalayan orogen and the extrusive eastward movement of the eastern Tibetan Plateau (Zhong et al., 1998; Pan 1999). The following are three representative phenomena for the active geology in the local region.

- Many deep faults are still active at present. Those active faults include the left-slip Dongjiu Fault, the huge-scale right-slip Jiali Fault, the right-slip Zayu Fault, the right-slip Guyu Fault, and others (Figure 1) (Ding and Zhong, 1999; Ren et al., 2000; Ying et al., 1999; BGMRXAR, 1993, 1994; 1995).

- Terraces on the banks of rivers and stream courses are a common phenomenon. The terraces can have one to three platforms. The terrace slopes can have variable heights. The terrace heights are commonly between 10 and $20 \mathrm{~m}$. A typical example is the terraces on the Parlung-Tsangpo River. These unique terraces represent the alternating activity and equilibrium of the crust uplift and stream undercutting.

- There is frequent seismic activity.

Therefore, it is clear that the local geological background is extremely active and complicated. Any engineering constructions and projects will have to face the challenges and damage of the extremely unfavorable geological conditions. There has always been high potential for the occurrence of slope failures. These failures would cause high cost in economy and human life if human activities and engineering projects were located at those zones of high slope failure potential.

\section{Main slope failures along the highway section}

Besides the active geological factors discussed above, there are many other factors that also contribute to the occurrence of slope failures. The other factors are high precipitation, landform, glaciers, water in streams and under ground, physical weathering and high daily temperature variations. Under the multiple actions of these factors, slope failures are very common and have different types. Based on the present investigation, the slope failures can be classified into the following five types: a) landslide, b) mud-rock flow, c) debris flow, d) avalanche, e) grain flow. The debris volumes have an extremely wide range from a few cubic meters to billions of cubic meters.

Figure 1 shows the distribution of these existing slope failures in the local region. Table 1 gives a summary of the numbers of existing slope failures along the highway section. The debris flow is widely spread, which is not to be described here. From Figure 1 and Table 1, it is clear that the huge-scale slope failures mainly occur at the region between Lulang and Ranwu. They are especially concentrated in the region between Dongjiu and Tongmai. Representative failure cases are the Dongjiu landslide, the Layue collapse, the Peilong mud-rock flow, the Peilong avalanche, the Yigong landslide, the Jiamaqimei mud-rock flow and the 102 landslide.

\section{Landslides}

The present investigation observed that the majority of the landslides happened along the highway between Dongjiu and Bomi. The landslides comprised mainly the kame moraine and contragradation deposits. They are usually caused by stream erosion at the natural slope toes. They can be classified as tractional landslides. Below, we will briefly present some major landslide cases.

\section{The Dongjiu Landslides}

As shown in Plate 1, the Dongjiu Landslides consist of a set of multiple landslides. The first landslide occurred in September 1991. The slope comprised Quaternary kame moraine and is located on the Lulang River. The slope had a dip angle $50^{\circ}$. The slope is located near and above the highway. The landslides were controlled by the active Dongjiu Fault and triggered by water scouring in the stream course at the slope toe. The remaining unstable slope masses progressively jointed together to form a huge landslide. There seems no plan to carry out engineering work to prevent the reoccurrence of a potential huge landslide in the near future.

\section{The Yigong Landslide}

In 1900, a super-large landslide occurred at Zhamu Creek. The landslide debris had a volume of up to 300 million cubic meters. The landslide blocked the Yigong River at the slope toe and thus formed the Yigong Lake. The landslide dam failed one to two months after the landslide event. A large amount of the lake water suddenly flowed down and caused flooding in the river downstream. The fl 